\title{
EFFICIENT SYNTHESIS OF NOVEL TRICYCLIC BENZOXAZINE DERIVATIVE VIA RING OPENING OF EPOXIDE ALONG THE MP AND DFT STUDIES OF STRUCTURAL, SPECTROSCOPIC (IR, RAMAN, UV-VIS), THERMODYNAMIC, ORBITALS AND NLO PROPERTIES OF DESIRED TRICYCLIC BENZOXAZINE DERIVATIVE
}

\author{
ASIM MANSHA ${ }^{1}$, AMEER FAWAD ZAHOOR ${ }^{1,2^{*}}$, FAISAL MAQBOOL ZAHID $^{3}$, SADIA ASIM ${ }^{4}$ \\ AND SHAHLA FAISAL ${ }^{3}$
}

\begin{abstract}
${ }^{1}$ Department of Chemistry, Government College University Faisalabad, Faisalabad-38000, Pakistan. ${ }^{2}$ Institut für Organische Chemie, Universität des Saarlandes, D-66123 Saarbrücken, Germany.

${ }^{3}$ Department of Statistics, Government College University Faisalabad, Faisalabad-38000, Pakistan.

${ }^{4}$ Department of Chemistry, Government College Women University Faisalabad, Faisalabad, Pakistan.
\end{abstract}

\begin{abstract}
Ring opening of 2-nitro phenyl glycidyl ether by chelated amino acid ester enolate provides access to desired novel benzoxazine derivative just over a few steps. Theoretical study on the molecular structure of 2,2,2-trifluoro- $N$-(1-oxo-2,3,3a,4-tetrahydro-1 $H$-benzo[b]pyrrolo[1,2-d][1,4]ox-azin-2-yl) acetamide (S11) is presented by using second order Møller Plesset (MP2) as well as density functional theory (DFT) level calculations. The calculated vibrational frequencies were assigned into normal modes of vibration by the use of potential energy distribution (PED). The positive charge on all hydrogen atoms were obtained by charge distribution calculations using Mulliken, electrostatic and natural charge distributions. Similar electrophilic and nucleophilic regions were observed from the calculated electrostatic potential surface calculations. The time dependent density functional theory (TD-DFT) calculations were performed to obtain electronic transitions within the molecule. The frontier molecular orbital (FMO) analysis was leading to the possible charge transfer within the molecule. The natural bond orbital (NBO) analysis provided information regarding the interaction between the donor and acceptor in bond. The changes in statistical thermodynamic functions (dipole moment, internal energy, enthalpy, Gibbs free energy, entropy, heat capacities and partition functions) were calculated at the range of temperature from 10-500 K.
\end{abstract}

Keywords: Chelated enolates, Ring opening, Benzoxazine, DFT, NBO.

\section{INTRODUCTION}

The benzoxazine moiety is a fascinating scaffold which constitutes important structural feature of different pharmaceutically important drugs such as Bemoradan (1) (vasodilator agent), Azasetron (2) (serotonin 3 antagonistic) and Levofloxacin (3) (antibiotic) [1] (Figure 1). Various 1,4-benzoxazine derivatives have the ability to act as central nervous system depressants [2,3], antipsychotic agents [4], calcium antagonists [5] and antibacterial agents [6,7].

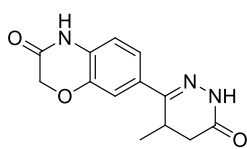

(1)

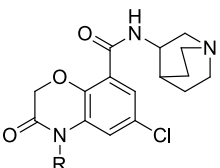

(2)
(3)

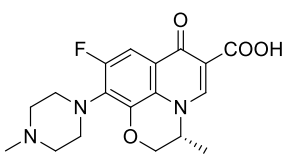

Figure 1. Structures of Bemoradan (1), Azasetron (2) and Levofloxacin (3).

Promoted by the pharmacological properties exhibited by benzoxazine bearing molecules, various novel methods for the synthesis of this scaffold have been reported such as iodocyclization [8], tandem reduction-oxirane opening of 2nitroaroxymethyloxiranes [9], Baeyer-Villiger oxidation reaction [10] and Pdcatalyzed aerobic oxidation of $o$-aminophenols with isocyanides [11]. In addition to this, ring opening reaction of spirocyclic epoxide with 2-haloanilines [12] proved to be a competent approach to construct spirocyclic-3,4-dihydro- $2 \mathrm{H}$ benzo $[b][1,4]$ oxazine derivatives.

Previously, we reported the epoxides ring opening with chelated amino acid ester enolates [13] as well as their synthetic applications [14-16]. Herein, we report the synthesis of 1,4-benzoxazine scaffold via same methodology. Ring opening of 2-nitro phenyl glycidyl ether with chelated amino acid ester enolate followed by oxidation with Dess-Martin periodinane, reductive amination and subsequent intramolecular $\mathrm{N}$-acylation afforded the desired tricyclic benzoxazine derivative. Here, we also represent the detailed structural properties of 2,2,2-trifluoro- $N$-(1-oxo-2,3,3a,4-tetrahydro- $1 H$-benzo[b]pyrrolo[1,2-d][1,4] ox-azin-2-yl) acetamide (S11) in gas phase using B3LYP correlation at second order Møller Plesset (MP2) as well as the density functional theory (DFT). The chemical stability of $\mathbf{S 1 1}$ makes it attractive candidate for known pharmaceutical properties of tricyclic benzoxazine derivatives [17,18]. In the view of applications of S11, the MP2 calculations at B3LYP/6-311++G level and the DFT calculations at B3LYP/6-311+G, B3LYP/6-311++G level were performed for geometric parameters (bond energy, bong length and dihedral angles) and vibrational frequencies. The vibrational frequencies (Infra-red (IR) and Raman spectra) were assigned in the normal modes of vibration using the potential energy distribution (PED) calculations. The charge distributions were calculated with Mulliken, electrostatic and natural charge distributions. Natural bond orbitals (NBO) analysis was performed for obtaining interactions in the bond. The molecular electrostatic potential surface (ESP) was calculated for mapping the electrophilic and nucleophilic sites. The electronic absorption spectra and frontier molecular orbital (FMO) analysis were reflecting the possible transition in subjected molecule. The change in thermodynamic functions like contribution to the partition function $(\mathrm{Q})$, internal energy $(\Delta \mathrm{U})$, Gibbs free energy $(\Delta \mathrm{G})$, entropy $(\Delta \mathrm{S})$, enthalpy $(\Delta \mathrm{H})$, heat capacity (cv and cp) and dipole moment $(\mu)$ were calculated in the range of temperature.

\section{EXPERIMENTAL}

\section{Materials and Methods}

${ }^{1} \mathrm{H}$ NMR and ${ }^{13} \mathrm{C}$ NMR spectra were recorded in $\mathrm{CDCl}_{3}$ on a Bruker Advance II $400 \mathrm{MHz}$ NMR spectrometer using TMS as internal reference. Products were identified with thin layer chromatographic technique using precoated Polygram SIL-G/UV 254 plates (Macherey-Nagel, Düren). Purification was done by flash chromatography on silica gel $(0.063-0.2 \mathrm{~mm})$ using the mixture of ethyl acetate and n-hexane as eluent. Commercially available solvents were distilled prior to use.

Synthesis of 2,2,2-trifluoro- $N$-(1-oxo-2,3,3a,4-tetrahydro-1 $H$-benzo[b] pyrrolo[1,2-d][1,4]ox-azin-2-yl) acetamide (S11)

A solution of dihydrobenzoxazine amino acid $\mathbf{1 0}(50 \mathrm{mg}, 0.13 \mathrm{mmol})$ in toluene (dry, $2.2 \mathrm{~mL}$ ) in the presence of DMAP ( $8 \mathrm{mg}, 50 \mathrm{~mol} \%$ ) was refluxed under nitrogen atmosphere for around $4 \mathrm{hrs}$ and then cooled to r.t and diluted with DCM. The mixture was washed with $1 \mathrm{~N} \mathrm{HCl}$, water and brine. The organic layer was dried using $\mathrm{Na}_{2} \mathrm{SO}_{4}$, solvent was removed in vacuo and purified by column chromatography (silica, hexane/EtOAc 8:2) to obtain desired 
benzoxazine $\mathbf{S 1 1}$ in 20\% yield (ratio 6.5:3.5) as a colorless solid. M. p. $58{ }^{\circ} \mathrm{C}$. Major diastereomer: ${ }^{1} \mathrm{H} \mathrm{NMR}\left(400 \mathrm{MHz}, \mathrm{CDCl}_{3}\right): \delta=8.37\left(\mathrm{dd},{ }^{3} J_{10,9}=8.2 \mathrm{~Hz}\right.$, $\left.{ }^{3} J_{10,11}=1.5 \mathrm{~Hz}, 1 \mathrm{H}, 10-\mathrm{H}\right), 7.32$ (bs, $\left.1 \mathrm{H}, \mathrm{N}-\mathrm{TFA} \mathrm{H}\right), 6.94-7.11(\mathrm{~m}, 3 \mathrm{H}, 9-\mathrm{H}, 11-$ $\mathrm{H}, 12-\mathrm{H}), 4.66\left(\mathrm{ddd},{ }^{3} J_{3,6 \mathrm{a}}=11.4 \mathrm{~Hz},{ }^{3} J_{3,6 \mathrm{~b}}=8.0 \mathrm{~Hz},{ }^{3} J_{3, \mathrm{NHTFA}}=5.4 \mathrm{~Hz}, 1 \mathrm{H}, 3-\mathrm{H}\right)$, $4.45\left(\mathrm{dd},{ }^{2} J_{7 \mathrm{a}, 7 \mathrm{~b}}=11.0 \mathrm{~Hz},{ }^{3} J_{7 \mathrm{a}, 5}=3.2 \mathrm{~Hz}, 1 \mathrm{H}, 7 \mathrm{a}-\mathrm{H}\right), 3.90-4.03(\mathrm{~m}, 1 \mathrm{H}, 5-\mathrm{H})$, $3.54\left(\mathrm{dd},{ }^{2} J_{7 \mathrm{~b}, 7 \mathrm{a}}={ }^{3} J_{7 \mathrm{~b}, 5}=10.5 \mathrm{~Hz}, 1 \mathrm{H}, 7 \mathrm{~b}-\mathrm{H}\right), 3.04\left(\mathrm{ddd},{ }^{2} J_{6 \mathrm{a}, 6 \mathrm{~b}}=12.4 \mathrm{~Hz},{ }^{3} J_{6 \mathrm{a}, 3}=\right.$ $\left.8.0 \mathrm{~Hz},{ }^{3} J_{6 \mathrm{a} .5}=5.8 \mathrm{~Hz}, 1 \mathrm{H}, 6 \mathrm{a}-\mathrm{H}\right), 1.53-1.61(\mathrm{~m}, 1 \mathrm{H}, 6 \mathrm{~b}-\mathrm{H}) .{ }^{13} \mathrm{C}$ NMR $(100$ $\left.\mathrm{MHz}, \mathrm{CDCl}_{3}\right): \delta=167.6,157.2(\mathrm{q}, J=38.8 \mathrm{~Hz}), 144.8,125.8,123.5,121.7$, $119.1,117.3,115.5(\mathrm{q}, J=285.8 \mathrm{~Hz}), 68.6,51.2,50.7,29.9$. Minor diastereomer (selected signals): ${ }^{1} \mathrm{H}$ NMR $\left(400 \mathrm{MHz}, \mathrm{CDCl}_{3}\right)$ : $\delta=6.93-7.09(\mathrm{~m}, 3 \mathrm{H}, 9-\mathrm{H}, 11-$ $\mathrm{H}, 12-\mathrm{H}), 4.66\left(\mathrm{ddd},{ }^{3} J_{3,6 \mathrm{a}}=11.3 \mathrm{~Hz},{ }^{3} J_{3,6 \mathrm{~b}}=7.9 \mathrm{~Hz},{ }^{3} J_{3, \mathrm{NHTFA}}=4.4 \mathrm{~Hz}, 1 \mathrm{H}, 3-\mathrm{H}\right)$, $4.45\left(\mathrm{dd},{ }^{2} J_{7 \mathrm{a}, 7 \mathrm{~b}}=10.9 \mathrm{~Hz},{ }^{3} J_{\mathrm{7a}, 5}=3.6 \mathrm{~Hz}, 1 \mathrm{H}, 7 \mathrm{a}-\mathrm{H}\right), 3.90-4.03(\mathrm{~m}, 1 \mathrm{H}, 5-\mathrm{H})$.

\section{RESULTS AND DISCUSSION}

\section{Chemistry}

Chelated amino acid ester enolates prove to be excellent candidates as nucleophiles for the ring opening of epoxides and give primary or secondary alcohols depending upon epoxide structure. Terminal primary alcohols are obtained in case of aryl epoxides as a result of the attack by the enolate at the benzylic position. On the other hand, $\gamma$-hydroxy amino acid $\mathbf{5}$ is obtained by the attack of enolate at sterically least substituted carbon of the epoxide ring. After Dess-Martin oxidation, alcohol $\mathbf{5}$ is converted into $\gamma$-oxo amino acid $\mathbf{6}$ with excellent yield range (Scheme 1) [16].

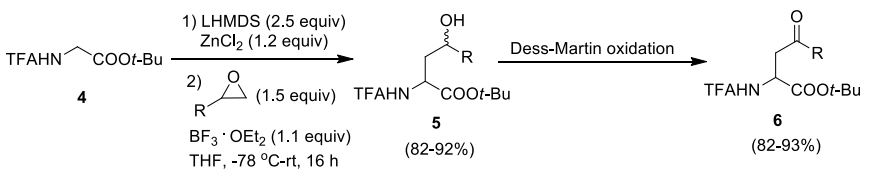

\section{$\mathrm{R}=\mathrm{Me}, \mathrm{Bu}, \mathrm{CH}_{2} \mathrm{Cl}, \mathrm{CH}_{2} \mathrm{OPh}, \mathrm{CH}_{2} \mathrm{O}\left(\mathrm{C}_{6} \mathrm{H}_{4} \mathrm{Cl}-4\right)$,}

$\mathrm{CH}_{2} \mathrm{O}\left(\mathrm{C}_{6} \mathrm{H}_{4} \mathrm{CN}-2\right), \mathrm{CH}_{2} \mathrm{O}\left(\mathrm{C}_{6} \mathrm{H}_{4} \mathrm{NO}_{2}-2\right)$

Scheme 1. Synthesis of $\gamma$-oxo amino acid 6 [16].

In order to access the desired benzoxazine derivatives, we chose 2-nitro phenyl glycidyl ether $\mathbf{8}$ for ring opening reaction. Regioselective ring opening of 2-nitro phenyl glycidyl ether $\mathbf{8}$ by chelated amino acid ester enolate $\mathbf{7}$ led to the formation of respective $\gamma$-hydroxy amino acid in $84 \%$ yield which after DessMartin oxidation could be converted into $\gamma$-keto amino acid $\mathbf{9}$ in 87\% yield [13]. Subsequently, under reduction-reductive amination process, nitro group of the $\gamma$ keto amino acid $\mathbf{9}$ was reduced to afford the cyclized compound dihydrobenzoxazine amino acid $\mathbf{1 0}$ in excellent yield [16]. Finally, upon treatment with dimethylaminopyridine (DMAP), amino acid $\mathbf{1 0}$ could be converted into the desired tricyclic benzoxazine derivative $\mathbf{1 1}$ in $20 \%$ yield (Scheme 2)

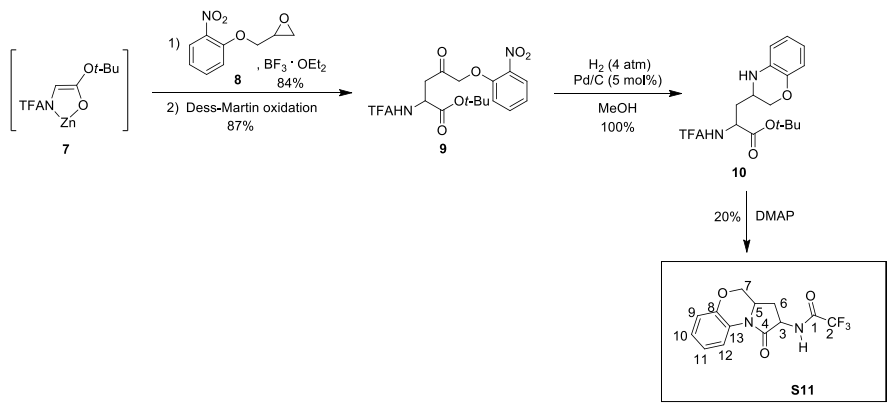

Scheme 2. Synthesis of benzoxazine derivative S11.

\section{Computational detail}

The Gaussian 16W program package [19] was used to perform all the quantum chemical calculations. The $\mathbf{S 1 1}$ structure was optimized with Hatree Fock (HF) level first with $\mathrm{HF} / 6-31+\mathrm{G}$ level and then fully re-optimized at B3LYP/6-31+G, B3LYP/6-311++G and MP2/6-311++G without symmetry restriction. The B3LYP is a hybrid function which was proposed for the main group structures, non-covalent interactions, frequency analysis, FMO analysis, electronic transitions, NBO analysis, thermodynamics and kinetics investigations $[20,21]$ was used in the current study. In order to confirm the stability of optimized structure, frequency calculations was performed and the absence of any imaginary frequency reflected the nature of stationary point as minimum on potential energy surface. The systematic overestimated vibrational frequencies were scaled by $0.9688[22,23]$. The calculated vibrational frequencies were assigned into normal modes of vibration based on the PED using VEDA 4 program [24] and Gauss view program (providing visual inspection). The bonding interactions of S11 were also investigated with Gaussian 16W using natural bond orbital (NBO) analysis. It is based on the process that combines the concept of canonical delocalized HF molecular orbitals (MOs) theory with the localized MOs theory using the sequential transformation. The localized MOs have close tied with the concept of chemical bonding. In this sequential transformation process the set of natural atomic orbitals (NAOs), natural hybrid orbitals (NHOs) and natural bond orbitals (NBOs) are obtained from the nonorthogonal atomic orbitals (AOs). The minimum filled NBOs are used to describe localized basis sets, which results in the localized Lewis structure. The interaction of Rydberg orbitals (or anti-bonding orbitals) with filled orbitals resulted in deviation from the Lewis structure. This interaction is the measure of delocalization. The charge transfer interactions arising from the non-covalent bonding and anti-bonding is the quantitative measure of the second order perturbation interaction energy $\left(\mathrm{E}^{2}\right)$ [25-27]. The TD-DFT calculations in vacuo by using the polarized continuum model (PCM) were performed for the UV absorption spectra of S11 with the hybrid exchange function B3LYP [20,21], and the gradient based exchange and correction functions B3PW91 [28] and PBEPBE $[29,30]$

\section{Structural analysis}

In the Figure 2 (a) the structure of $\mathbf{S 1 1}$ is shown with atomic numbering and in the Figure 2 (b) is the optimized structure of S11 in gas phase along with the Cartesian coordinate axis at B3LYP/6-311++G level. The crystal structure of S11 is neither reported in the literature and nor can be recorded. In the Table 1 are given the geometric parameters like bond lengths, the selected bond angles and dihedral angles using MP2/6-311++G, B3LYP/6-31+G and B3LYP/6-311++G. The MP2 method has advantage over the DFT method that it is free from the spurious self-interaction of electrons considered in the DFT, rather it naturally take dispersion into account. But, at the same time it has turned into deficiency when the interaction of molecular segments is calculated [31]. The molecular structure is a non-planner structure. For C2 - C6 bond length is $1.403 \AA$ while $\mathrm{C} 1-\mathrm{C} 2$ is $1.389 \AA$ and is due to the $\pi$ electron delocalized system. While C9 $\mathrm{C} 10$ bond is $1.539 \AA$ long this may be due to electronegative effect of oxygen and nitrogen in the surrounding, causing the electron withdrawing effect. The computed bond length for $\mathrm{C} 6-\mathrm{N} 8$ is $1.417 \AA$ which is somewhat smaller than average value of single $\mathrm{C}-\mathrm{N}$ bond (1.47) while $\mathrm{C} 12-\mathrm{N} 15$ (1.462 $\AA$ ) has value closer to the average value [32]. The $\mathrm{C}-\mathrm{O}$ double bond is in the range of 1.239 $\AA$ to $1.241 \AA$ and is close to the reported values [33]. Figure 3 represents the connectivity of bond lengths and selected bond angles. The $\mathrm{C}-\mathrm{O}-\mathrm{C}$ bond angle is reported as $117.9^{\circ}$ for methoxy group and calculated $\mathrm{C} 2-\mathrm{O} 7-\mathrm{C} 9$ as $113.6^{\circ}$ in the ring [32]. For the $\mathrm{C} 2-\mathrm{O} 7-\mathrm{C} 9$ bond, angle was calculated as $113.6^{\circ}$ (reported as in range of $110.5^{\circ}$ ) and of $\mathrm{C} 6-\mathrm{N} 8-\mathrm{C} 13$ as $126.0^{\circ}$ (reported as in the range of $121.5^{\circ}$ ), this difference is due to nitrogen atom as being nearly trigonal planar [32-34]. The two six member rings have dihedral angle (C6 - N8 $-\mathrm{C} 10-\mathrm{C} 9)$ as $22.8^{\circ}$ and were almost coplanar. The oxazine ring has almost halfchair conformation with dihedral angle of $\mathrm{C} 6-\mathrm{C} 2-\mathrm{O} 7-\mathrm{C} 9$ is $44.3^{\circ}$ [35].

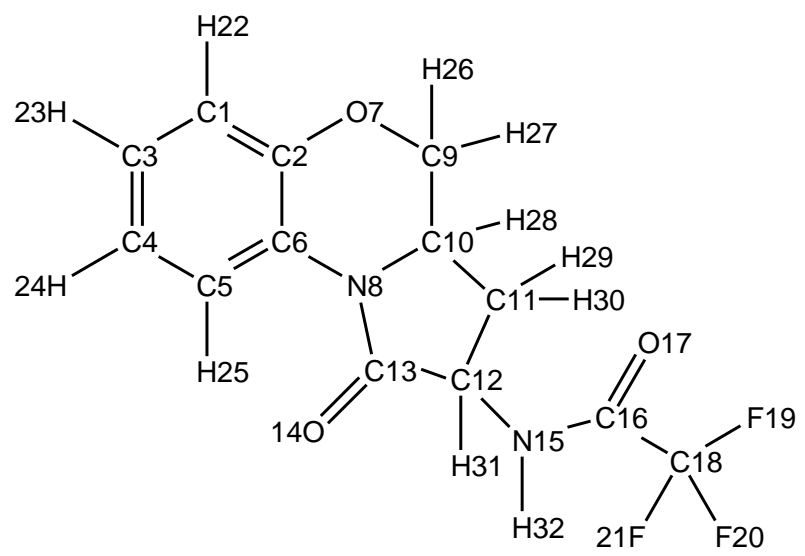




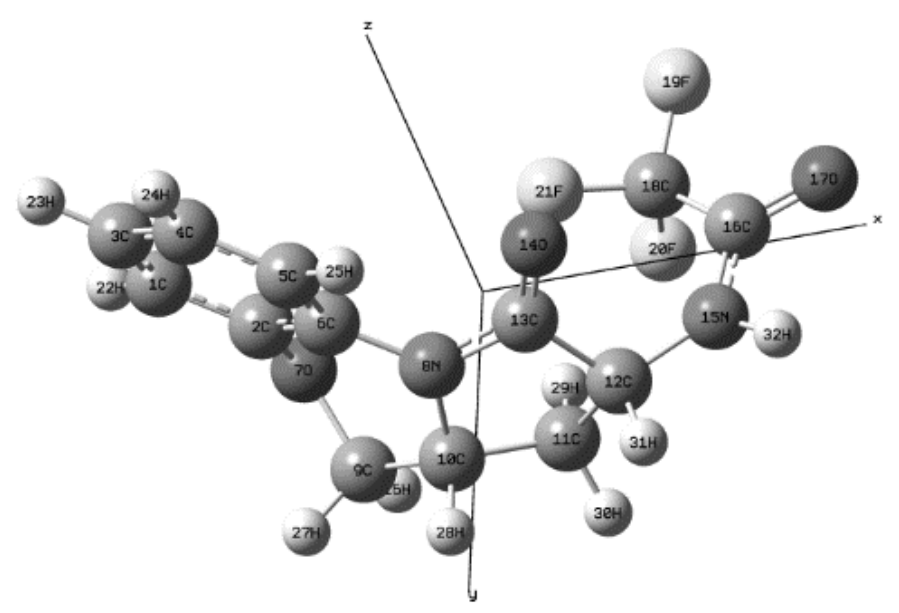

Figure 2. Structure S11 with the atomic numbering and the optimized molecular structure of S11 with DFT/6-311++G in Vacuo along with the Cartesian coordinate axis.
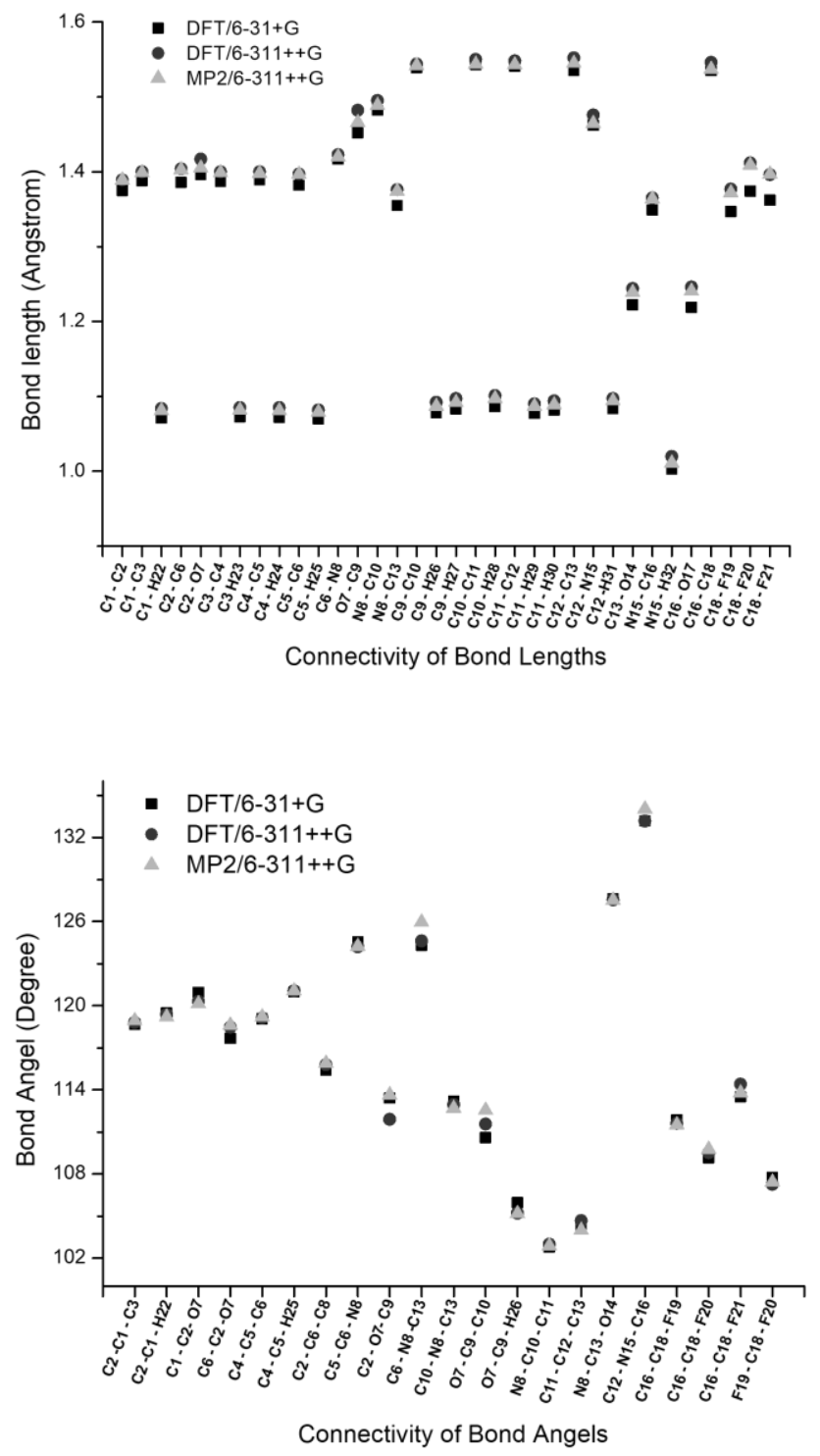

Figure 3. Selected geometric parameters: (a) Bond length and (b) Bond Angle, of structure S11 computed with B3LYP/6-31+G, /B3LYP/6-311++G and MP2/6-311++G.
Table 1. Selected geometric parameters (bond lengths, bond angles and dihedral angles) of S11 computed with MP2/6-311++G, B3LYP/6-31+G, and B3LYP/6-311++G in gas phase.

\begin{tabular}{|c|c|c|c|}
\hline \multirow{2}{*}{ Parameters } & \multicolumn{3}{|c|}{ bond lengths $(\AA)$, bond angles $\left({ }^{\circ}\right)$ and dihedral angles $\left({ }^{\circ}\right)$} \\
\hline & B3LYP/6-31+G & B3LYP/6-311++G & MP2/6-311++G \\
\hline $\mathrm{C} 1-\mathrm{C} 2$ & 1.375 & 1.389 & 1.389 \\
\hline C $1-\mathrm{C} 3$ & 1.388 & 1.400 & 1.399 \\
\hline $\mathrm{C} 1-\mathrm{H} 22$ & 1.071 & 1.084 & 1.081 \\
\hline $\mathrm{C} 2-\mathrm{C} 6$ & 1.386 & 1.404 & 1.403 \\
\hline $\mathrm{C} 2-\mathrm{O} 7$ & 1.396 & 1.417 & 1.405 \\
\hline $\mathrm{C} 3-\mathrm{C} 4$ & 1.387 & 1.400 & 1.399 \\
\hline C $3-\mathrm{H} 23$ & 1.073 & 1.085 & 1.082 \\
\hline $\mathrm{C} 4-\mathrm{C} 5$ & 1.389 & 1.400 & 1.398 \\
\hline C $4-\mathrm{H} 24$ & 1.072 & 1.085 & 1.081 \\
\hline C 5-C 6 & 1.382 & 1.397 & 1.397 \\
\hline C $5-\mathrm{H} 25$ & 1.070 & 1.082 & 1.079 \\
\hline $\mathrm{C} 6-\mathrm{N} 8$ & 1.417 & 1.423 & 1.420 \\
\hline $\mathrm{O} 7-\mathrm{C} 9$ & 1.452 & 1.482 & 1.466 \\
\hline N $8-$ C 10 & 1.482 & 1.495 & 1.489 \\
\hline N $8-$ C 13 & 1.355 & 1.376 & 1.374 \\
\hline C 9-C 10 & 1.539 & 1.544 & 1.542 \\
\hline C 9-H 26 & 1.078 & 1.092 & 1.087 \\
\hline C 9-H 27 & 1.083 & 1.097 & 1.092 \\
\hline C $10-\mathrm{C} 11$ & 1.543 & 1.550 & 1.544 \\
\hline C $10-$ H 28 & 1.086 & 1.101 & 1.097 \\
\hline C $11-\mathrm{C} 12$ & 1.541 & 1.548 & 1.543 \\
\hline C $11-$ H 29 & 1.077 & 1.090 & 1.087 \\
\hline C $11-$ H 30 & 1.082 & 1.094 & 1.089 \\
\hline C $12-$ C 13 & 1.535 & 1.552 & 1.545 \\
\hline $\mathrm{C} 12-\mathrm{N} 15$ & 1.462 & 1.476 & 1.465 \\
\hline C $12-$ H 31 & 1.084 & 1.097 & 1.094 \\
\hline $\mathrm{C} 13-\mathrm{O} 14$ & 1.222 & 1.244 & 1.239 \\
\hline N $15-$ C 16 & 1.349 & 1.365 & 1.364 \\
\hline N $15-$ H 32 & 1.003 & 1.020 & 1.011 \\
\hline C $16-O 17$ & 1.219 & 1.246 & 1.241 \\
\hline C $16-$ C 18 & 1.535 & 1.546 & 1.537 \\
\hline C $18-$ F 19 & 1.347 & 1.377 & 1.372 \\
\hline C $18-$ F 20 & 1.374 & 1.412 & 1.409 \\
\hline C $18-\mathrm{F} 21$ & 1.362 & 1.396 & 1.397 \\
\hline $\mathrm{C} 2-\mathrm{C} 1-\mathrm{C} 3$ & 118.7 & 118.8 & 118.9 \\
\hline $\mathrm{C} 2-\mathrm{C} 1-\mathrm{H} 22$ & 119.5 & 119.4 & 119.2 \\
\hline $\mathrm{C} 1-\mathrm{C} 2-\mathrm{O} 7$ & 121.0 & 120.3 & 120.2 \\
\hline $\mathrm{C} 6-\mathrm{C} 2-\mathrm{O} 7$ & 117.7 & 118.5 & 118.6 \\
\hline $\mathrm{C} 4-\mathrm{C} 5-\mathrm{C} 6$ & 119.0 & 119.1 & 119.2 \\
\hline $\mathrm{C} 4-\mathrm{C} 5-\mathrm{H} 25$ & 121.0 & 121.0 & 121.0 \\
\hline $\mathrm{C} 2-\mathrm{C} 6-\mathrm{C} 8$ & 115.4 & 115.8 & 115.9 \\
\hline C $5-\mathrm{C} 6-\mathrm{N} 8$ & 124.5 & 124.2 & 124.2 \\
\hline C $2-\mathrm{O} 7-\mathrm{C} 9$ & 113.4 & 111.9 & 113.6 \\
\hline C $6-\mathrm{N} 8-\mathrm{C} 13$ & 124.3 & 124.6 & 126.0 \\
\hline $\mathrm{C} 10-\mathrm{N} 8-\mathrm{C} 13$ & 113.2 & 112.9 & 112.7 \\
\hline $\mathrm{O} 7-\mathrm{C} 9-\mathrm{C} 10$ & 110.6 & 111.6 & 112.6 \\
\hline O $7-\mathrm{C} 9-\mathrm{H} 26$ & 106.0 & 105.2 & 105.2 \\
\hline N $8-\mathrm{C} 10-\mathrm{C} 11$ & 102.8 & 103.0 & 102.9 \\
\hline C $11-$ C $12-$ C 13 & 104.3 & 104.7 & 104.0 \\
\hline $\mathrm{N} 8-\mathrm{C} 13-\mathrm{O} 14$ & 127.6 & 127.5 & 127.5 \\
\hline C $12-\mathrm{N} 15-\mathrm{C} 16$ & 133.2 & 133.2 & 134.0 \\
\hline C $16-$ C $18-$ F 19 & 111.9 & 111.6 & 111.5 \\
\hline C $16-$ C $18-$ F 20 & 109.1 & 109.5 & 109.8 \\
\hline C $16-$ C $18-F 21$ & 113.5 & 114.4 & 113.8 \\
\hline F $19-$ C $18-$ F 20 & 107.7 & 107.3 & 107.4 \\
\hline $\mathrm{C} 3-\mathrm{C} 1-\mathrm{C} 2-\mathrm{C} 6$ & 1.0 & 1.1 & 0.8 \\
\hline $\mathrm{C} 3-\mathrm{C} 1-\mathrm{C} 2-\mathrm{O} 7$ & -179.0 & -177.5 & -176.5 \\
\hline $\mathrm{C} 6-\mathrm{C} 2-\mathrm{O} 7-\mathrm{C} 9$ & 45.7 & 44.6 & 44.3 \\
\hline $\mathrm{C} 2-\mathrm{O} 7-\mathrm{C} 9-\mathrm{H} 27$ & 62.2 & 63.3 & 68.8 \\
\hline $\mathrm{C} 6-\mathrm{N} 8-\mathrm{C} 10-\mathrm{C} 9$ & 20.6 & 18.9 & 22.8 \\
\hline $\mathrm{C} 6-\mathrm{N} 8-\mathrm{C} 13-\mathrm{O} 14$ & 17.2 & 17.9 & 12.8 \\
\hline H $30-$ C11 - C12 - N15 & 83.6 & 85.4 & 79.9 \\
\hline C $12-\mathrm{N} 15-\mathrm{C} 16-\mathrm{O} 17$ & 172.4 & 173.1 & 171.7 \\
\hline N $15-$ C $16-$ C $18-$ F 19 & 157.5 & 158.9 & 163.7 \\
\hline O $17-$ C $16-$ C $18-$ F 20 & 92.1 & 93.0 & 98.1 \\
\hline
\end{tabular}

\section{Vibrational analysis}

The calculated and scaled vibrational wavenumber calculated with B3LYP/6$31+\mathrm{G}, \mathrm{B} 3 \mathrm{LYP} / 6-311++\mathrm{G}$ and MP2/6-311++G in gas phase are given in the Table 2 along with the vibrational assignments based on PED using VEDA 4 program. The calculated and scaled IR and Raman spectra are given in the 
Figure 4. The calculated vibrational wavenumbers are usually with the overestimated values due to neglect of anhormonicity. The use of B3LYP reduced this over estimation of wavenumber could be due to its correlation terms [36]. Use of scaling factor provides the better agreement of calculated and the observed wavenumbers [22,23]. For S11, 90 normal modes of vibrations were found. It is convenient to discuss vibrational assignment of the specific spectra regions.

\section{Nitrogen-hydrogen vibrations}

For compounds having $\mathrm{N}-\mathrm{H}$ bond, the stretching of $\mathrm{N}-\mathrm{H}$ is observed at 3500 to $3200 \mathrm{~cm}^{-1}$. The presence of hydrogen boning also effects the position of absorption band [37,38]. For $\mathrm{S} 11$, the $\mathrm{N}-\mathrm{H}$ stretching is calculated around 3465 $\mathrm{cm}^{-1}$ with $100 \%$ PED while at $3376 \mathrm{~cm}^{-1}$ with $81 \%$ PED. The relative broadening of $\mathrm{N}-\mathrm{H}$ stretching band is arising due to the presence of inter-molecular hydrogen bonding interactions $[32,39]$. Here, the $\mathrm{N}-\mathrm{H}$ bond acts as donor in the hydrogen bonding and resultantly observed red-shifting of stretching vibration [40].

\section{Carbon-hydrogen vibrations}

In the aromatic ring the stretching vibration of $\mathrm{C}-\mathrm{H}$ is reported in range of $3100 \mathrm{~cm}^{-1}$. The stretching of non-aromatic $\mathrm{C}-\mathrm{H}$ is reported around $3000 \mathrm{~cm}^{-1}$ $[25,41]$. The aromatic $\mathrm{C}-\mathrm{H}$ stretch have multiple weak bands. These vibrations are reported to have non-appreciable effect substitutions [34]. The vibrations calculated at 3123, 3100, 3014, 2961 and $2945 \mathrm{~cm}^{-1}$ are assigned to the stretching of $\mathrm{C}-\mathrm{H}$. While the vibrations calculated at 1488, 1428, 1382, 1352, 1337, 1216 and $1155 \mathrm{~cm}^{-1}$ are assigned as the in-plane bending with good agreements to reported range [38]. The vibrations at $650-450 \mathrm{~cm}^{-1}$ are reported as the out of plane bending of $\mathrm{C}-\mathrm{H}$ but are so weak in $\mathrm{S} 11$ to assign them. The possible reason behind it is the lesser negative charge on the carbon atoms resulting in decrease of dipole moment. This reduction is due to substitution resulting in electron withdrawal from carbon atom and causing decrease of inductive effect [42]. The presence of $\mathrm{CH}_{2}$ in $\mathrm{S} 11$ is contributing to $\mathrm{C}-\mathrm{H}$ vibrations with all six fundamental vibrational frequencies including two stretchings (symmetric and asymmetric), two bending (scissoring and rocking) modes and two in-plane and out-plane vibrations (wagging and twisting).

\section{Carbon-carbon vibrations}

The ring vibrations are much effected by the substitutions on the ring. The vibrations in the region of $1650-1300 \mathrm{~cm}^{-1}$ are reported as the ring vibrations $[43,44]$. For S11, the $\mathrm{C}-\mathrm{C}$ stretching ring vibrations are calculated at 1628 , $1586,1548,1533,1276$ and $1253 \mathrm{~cm}^{-1}$. These vibrational bands correlate well with the reported values [32]. The stretching vibrations of $\mathrm{C}-\mathrm{C}$ showed good intensity in the IR spectrum whereas they are of relatively lower intensity in the Raman spectrum. The doublet are formed due to presence of conjugation in substitution. The vibrations at higher wave number correlated to the in-plane deformation while the out-.plane vibrations are at lower wave numbers [43]. The vibrations calculated at $921,695,667,650,604,551,513 \mathrm{~cm}^{-1}$ and at 385,362 , $325,287,211,151,128 \mathrm{~cm}^{-1}$ are assigned to the in-plane bending vibrations and out of plane bending vibrations, respectively [45]. The small shifts in the calculated vibrational wavenumbers from the reported values are due to shift in the force constants due to extend of mixing of rings with substitutions.

\section{Carbon-oxygen vibrations}

The $\mathrm{C}-\mathrm{O}$ vibrations are quite sensitive to many factors. The nature of lone pair on oxygen will determine the force constant. Furthermore, the physical state, the substitutional effects and constrains on ring are important [43]. The vibrations in the region of $1740-1160 \mathrm{~cm}^{-1}$ are known as the carbonyl vibrations [26,36]. The symmetric stretch of $\mathrm{C}-\mathrm{O}$ is reported around $1020 \mathrm{~cm}^{-1}$ [46] while vibration around $1220 \mathrm{~cm}^{-1}$ is reported as asymmetric stretch of $\mathrm{C}-\mathrm{O}-\mathrm{C}$ [32]. For S11, the carbonyl stretching vibrations are calculated at 1628 and $1586 \mathrm{~cm}^{-1}$. The asymmetric stretching has been calculated at $1276 \mathrm{~cm}^{-1}$ and symmetric stretching around 1170 and $1050 \mathrm{~cm}^{-1}$. These calculated vibrations result in the stronger band in the IR spectrum while the weaker bands in the Raman spectrum. Mertan and co. reported that $\mathrm{C}-\mathrm{F}$ vibrational frequencies are poorly predicted by the hybrid function as B3LYP due to its week prediction of harmonic frequencies [47]. They computed the harmonic $\mathrm{C}-\mathrm{F}$ stretching using the M06-2X functional basis. In the current work, MP2/6-311++G also not computed any appreciable $\mathrm{C}-\mathrm{F}$ vibrations.
Table 2. Calculated and scaled vibrational wavenumber with vibrational assignments using potential energy distribution (PED).

\begin{tabular}{|c|c|c|c|c|c|}
\hline \multirow{3}{*}{$\begin{array}{c}\text { Sr } \\
\text { No. }\end{array}$} & \multicolumn{4}{|c|}{ Calculated wavenumbers $\left(\mathrm{cm}^{-1}\right)$} & \multirow{3}{*}{$\begin{array}{l}\text { Vibrational assignments } \\
\text { (\% PED) }\end{array}$} \\
\hline & \multicolumn{3}{|c|}{ DFT /Gas phase } & \multirow{2}{*}{\begin{tabular}{|c|} 
MP2 / gas \\
$(6-311++G(d, p))$ \\
\end{tabular}} & \\
\hline & 6-31+G (d,p) & 6-311++G (d,p) & 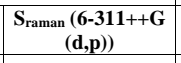 & & \\
\hline 1 & & 3465 & 28.26 & & $v_{N H}(100)$ \\
\hline 2 & 3376 & & 7.94 & 3376 & $v_{N H}(81)$ \\
\hline 3 & & 3123 & 34.11 & & $v_{\mathrm{CH}}(97)$ \\
\hline 4 & 3099 & 3093 & 66.73 & 3100 & $v_{\mathrm{CH}}(49)$ \\
\hline 5 & & 3069 & 26.01 & & $v_{\mathrm{CH}}(33)$ \\
\hline 6 & 3068 & 3038 & 19.43 & & $v_{\mathrm{CH}}(49)$ \\
\hline 7 & 3022 & 3023 & 40.23 & 3014 & $v_{C H}(51)$ \\
\hline 8 & 2984 & 2976 & 83.02 & 2961 & $v_{\mathrm{CH}}(77)$ \\
\hline 9 & 2938 & 2938 & 101.88 & 2945 & $v_{C H}(42)$ \\
\hline 10 & & & 4.46 & 2900 & $v_{\mathrm{CH}}(45), v_{\mathrm{CCC}}(13)$ \\
\hline 11 & 2892 & 2876 & 57.04 & 2862 & $v_{\text {CCantism }}(26)$ \\
\hline 12 & & & 0.33 & 2802 & $v_{c c s y m}(66)$ \\
\hline 13 & & 1628 & 20.88 & 1628 & $v_{o c}(17), v_{C C}(24)$ \\
\hline 14 & 1592 & 1589 & 81.38 & 1586 & $v_{O C}(26), v_{C C}(18)$ \\
\hline 15 & 1561 & 1574 & 12.08 & 1548 & $v_{c C}(20)$ \\
\hline 16 & & & 0.94 & 1533 & $v_{C C}(11), v_{C H}(12)$ \\
\hline 17 & 1546 & 1488 & 26.01 & 1488 & $\gamma_{\text {НСH }}(40)$ \\
\hline 18 & 1469 & 1465 & 11.12 & 1450 & $\gamma_{\text {нсC }}(51)$ \\
\hline 19 & 1446 & 1418 & 11.83 & 1428 & $\gamma_{\text {НСH }}(88)$ \\
\hline 20 & 1384 & 1387 & 13.26 & 1382 & $\gamma_{\text {НСН }}(63)$ \\
\hline 21 & 1369 & 1372 & 22.74 & 1352 & $\gamma_{\text {НСН }}(13)$ \\
\hline 22 & 1346 & 1333 & 62.40 & 1337 & $\gamma_{\mathrm{HCH}}(21)$ \\
\hline 23 & 1307 & 1309 & 7.96 & 1299 & $\gamma_{\text {нос }}(18), \gamma_{\text {нсс }}(21)$ \\
\hline 24 & 1284 & 1286 & 8.84 & 1276 & $v_{\text {cc }}(40)$ \\
\hline 25 & 1230 & 1248 & 4.22 & 1253 & $v_{c c}(30)$ \\
\hline 26 & & 1201 & 20.63 & 1216 & $\gamma_{\text {HCC }}(22)$ \\
\hline 27 & 1184 & 1186 & 5.53 & 1170 & $v_{\mathrm{CCC}}(14), \tau_{\mathrm{HCCC}}(16)$ \\
\hline 28 & 1138 & 1147 & 1.83 & 1155 & $\gamma_{\text {нсс }}(31)$ \\
\hline 29 & 1115 & 1101 & 1.44 & 1118 & $v_{\mathrm{CC}}(18), \tau_{\mathrm{HCCC}}(17)$ \\
\hline 30 & 1069 & 1077 & 2.74 & 1072 & $\gamma_{\text {нос }}(37), \tau_{\text {нссс }}(11)$ \\
\hline 31 & 1031 & 1031 & 2.84 & 1050 & $v_{C C}(20), v_{O C}(11)$ \\
\hline 32 & 1015 & 992 & 2.47 & 1004 & $v_{o C}(13), \gamma_{\text {HCC }}(10)$ \\
\hline 33 & 931 & 945 & 2.66 & 967 & $\tau_{\text {HсcC }}(39)$ \\
\hline 34 & 877 & 868 & 1.51 & 921 & $v_{C C}(24)$ \\
\hline 35 & 846 & & 0.14 & 846 & $\gamma_{O C}(34)$ \\
\hline 36 & 769 & 751 & 7.25 & 732 & $\tau_{\text {HсCC }}(99)$ \\
\hline 37 & 708 & 713 & 5.12 & 695 & $v_{C C}(11), v_{O C}(16)$ \\
\hline 38 & & & 4.68 & 690 & $\tau_{\text {Hсcc }}(14), \omega_{\text {occc }}(27)$ \\
\hline 39 & 684 & 667 & 11.20 & 667 & $\tau_{\mathrm{cccc}}(12)$ \\
\hline 40 & 654 & & 0.95 & 650 & $\gamma_{c c c}(19)$ \\
\hline 41 & 623 & 621 & 6.15 & 604 & $\gamma_{\mathrm{ccc}}(40)$ \\
\hline 42 & 561 & 566 & 2.98 & 551 & $v_{O C}(14), v_{C C}(14)$ \\
\hline 43 & 523 & 527 & 6.65 & 513 & $\gamma_{\mathrm{occ}}(17), \gamma_{\mathrm{ccc}}(10), \gamma_{\mathrm{cco}}(45)$ \\
\hline 44 & 484 & 473 & 4.41 & 461 & $\omega_{0 c c c}(28)$ \\
\hline 45 & 454 & 450 & 3.44 & 441 & $\omega_{0 \text { cccc }}(32)$ \\
\hline 46 & 438 & & 1.57 & 438 & $\omega_{0 \circ c c c}(34)$ \\
\hline 47 & 384 & 395 & 2.54 & 385 & $\begin{array}{c}\gamma_{o c c}(13), \gamma_{c c c}(23), \omega_{0 c c c} \\
(21)\end{array}$ \\
\hline 48 & & 372 & 3.94 & 362 & $\gamma_{c c c}(13), \omega_{c c c c}(30)$ \\
\hline 49 & & 333 & 0.89 & 325 & $Y_{c c c}(10), \omega_{c c c c}(11)$ \\
\hline 50 & 300 & 294 & 0.69 & 287 & $v_{C C}(25), \gamma_{C c C}(21)$ \\
\hline 51 & 215 & 217 & 1.02 & 211 & $\gamma_{\text {ссC }}(31), \tau_{\text {носс }}(14)$ \\
\hline 52 & 169 & 155 & 1.43 & 151 & $\gamma_{c c c}(68)$ \\
\hline 53 & 131 & 132 & 1.18 & 128 & $\tau_{\mathrm{cccc}}(12), \omega_{0 \mathrm{occc}}(14)$ \\
\hline 54 & 107 & 101 & 2.96 & 98 & $\tau_{\mathrm{cccc}}(53)$ \\
\hline 55 & 62 & 54 & 2.27 & 52 & $\tau_{\operatorname{cccc}}(48)$ \\
\hline
\end{tabular}

Abbreviations: $v$-stretching, $\gamma$-bending, $\tau$-torsion, $\omega$-out of plane bending, sym.-symmetrical, anti sym.-anti symmetric. 
(a)

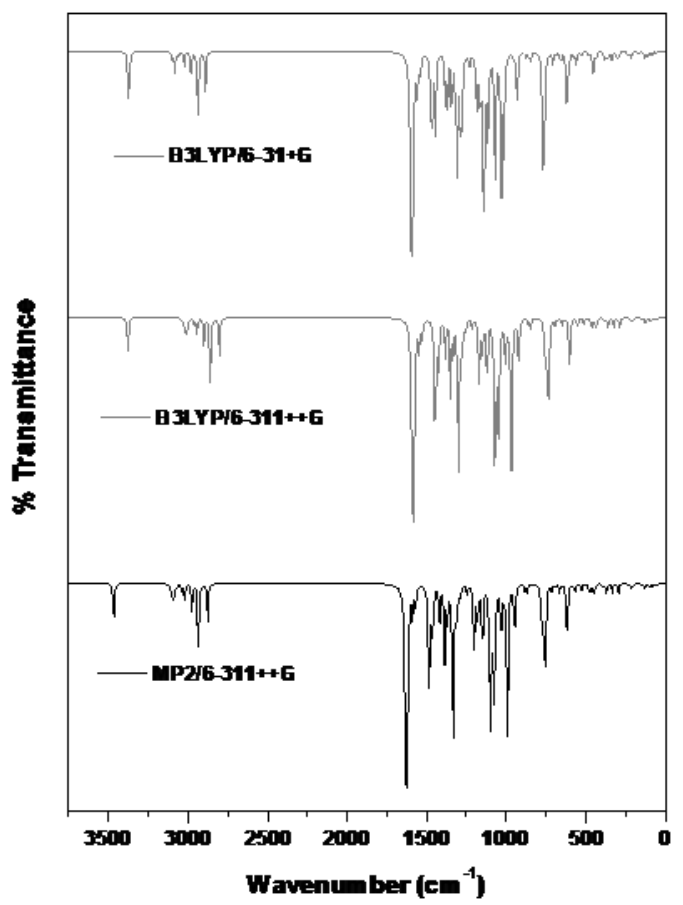

(b)

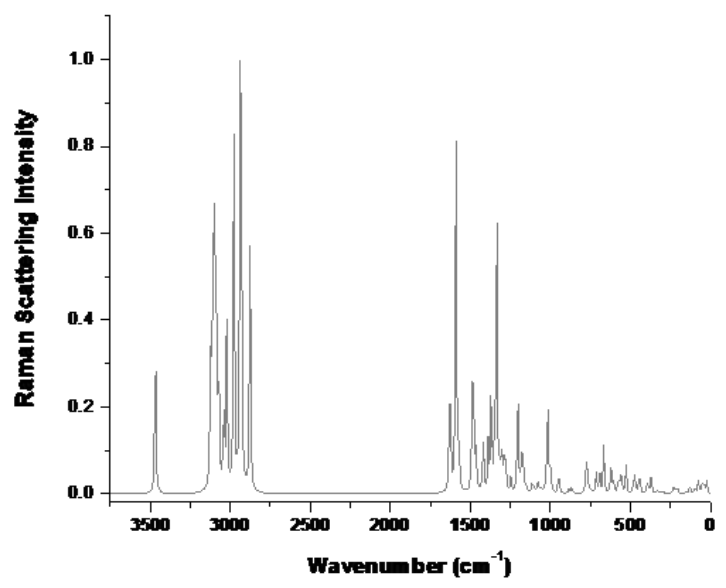

Figure 4. (a) Computed IR (scaled) spectra of S11 with B3LYP/6-31+G, B3LYP/6-311++G and MP2/6-311++G in gas phase and (b) computed Raman by MP2/6-311++G in gas phase.

\section{Atomic charge distribution}

The application of quantum calculations are closely related to the distribution of atomic charges in a molecule [48]. In this study, a comparison of Mulliken, electrostatic and NBO atomic charge distributions are given in the Figure 5. Similarly, the charge distributions calculated DFT and MP2 level are given in the Figure 5. Charge distribution is related to reactivity of the molecule and with the concept of chemical bonding. The comparison between Mulliken, electrostatic and NBO distributions is difficult because of very different level of theoretical backgrounds. $\mathrm{C} 2, \mathrm{C} 6, \mathrm{C} 9, \mathrm{C} 11, \mathrm{C} 12, \mathrm{C} 13, \mathrm{C} 16$ and $\mathrm{C} 18$ atoms have positive charge with both B3LYP and MP2. C1 shows -ve charge with B3LYP and +ve charge with MP2. The change of charge with change of basis set is due to change of polarization. $\mathrm{C} 3, \mathrm{C} 4$, and $\mathrm{C} 5$ carry negative charges while all hydrogen atoms possess positive charge. Maximum -ve charge is on nitrogen and then on $\mathrm{O} 14$ and O17. All three fluorine atoms also carry -ve charge. It explains the possible charge transfer from hydrogen to nitrogen and oxygen. The small variation of charge on $\mathrm{C}-\mathrm{O}$ and $\mathrm{N}-\mathrm{H}$ with Mulliken and natural charge distribution suggest that this molecule may have intermolecular interaction in the solid form [38]. It is reported that natural charge distribution is superior to in calculating atomic charges than the Mulliken charge distribution [49]. The charge distribution results are in accordance to the calculated potential energy surface of S11. (a)

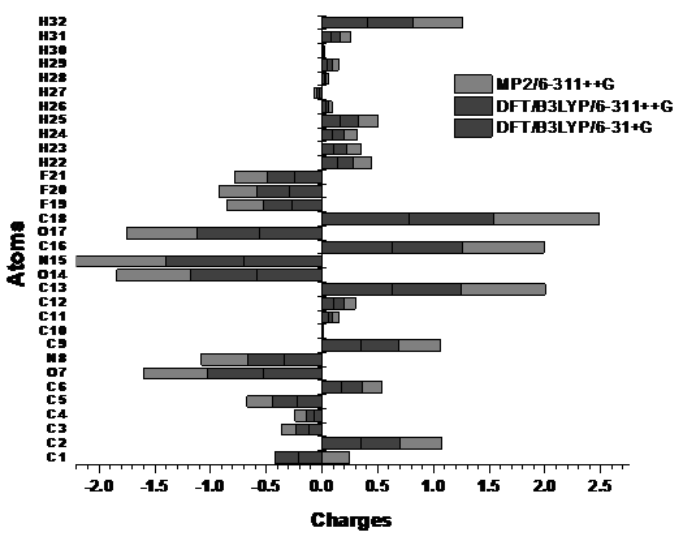

(b)

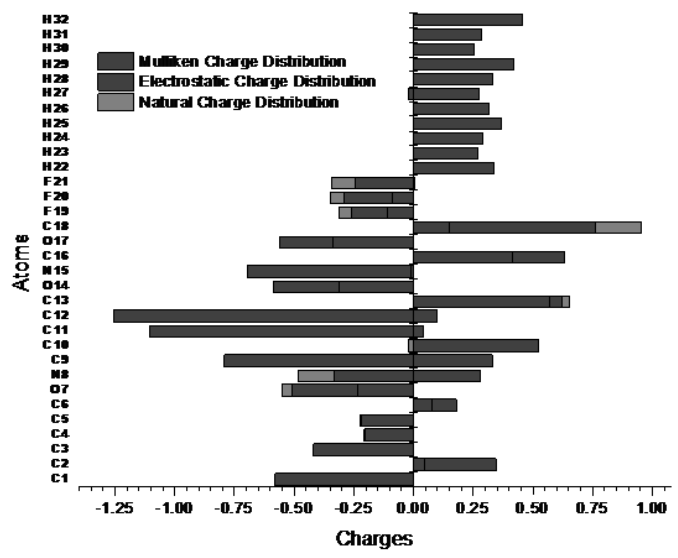

Figure 5. (a) Charge distribution graph of S11 using MP2 and DFT (b) Charge population computed by Mulliken, electrostatic and natural charge disruptions at B3LYP/6-311++G level.

\section{Natural bond orbital (NBO) analysis}

The main orbital interactions in S11 structure are obtained from NBO analysis. It provides with a tool to understand the individual chemical bonding and the energetic of lone-pair electrons that will determine the reactivity of the molecule in the chemical processes [50,53]. NBO analysis has provided information regarding hybridization, hydrogen bonding and the hyper-conjugation interactions. The second order perturbation energy $\left(E^{2}\right)$ is the quantitative measure of interactions between donor and acceptors in NBO and is also known as stabilization energy. The higher value of $\mathrm{E}^{(2)}$ is reflecting stronger interactions of donor and acceptor and the higher extend of conjugation [25]. The value of $\mathrm{E}^{(2)}$ depends on occupancy of donor (i) and acceptor (j), the diagonal elements (orbital energies) $\varepsilon_{i}$ and $\varepsilon_{j}$ and the off-diagonal Fork matix element, $F_{(i, j)}$ [54].

$$
E^{(2)}=\Delta E_{i j}=q_{i} \frac{F_{(i, j)}^{2}}{\varepsilon_{i}-\varepsilon_{j}}
$$

In the Table 3 are given the occupancy and other important information like the valance type data, directionally hybridization and the partial charges. The decrease of occupancy from the acceptor to the donor is reflecting the charge transfer from Lewis valence orbital to non-valence orbital.

The $\mathrm{E}^{(2)}$ analysis of selected donor and acceptor orbitals of $\mathbf{S 1 1}$ in gas phase are given in the Table 4 . It shows the pi conjugation resonance in the first benzene ring (arising from pi electrons delocalization) and the primary as well as secondary hyper-conjugation. The reason of pi conjugation is the $\pi \rightarrow \pi^{*}$ interactions whereas, the hyper-conjugation interactions are arising due to $\rightarrow \pi^{*}$ , $\pi \rightarrow \sigma^{*}$ and $n \rightarrow \sigma^{*}$ orbital overlaps. The secondary hyper-conjugation is due to $\sigma \rightarrow \sigma^{*}$ orbital overlap. Delocalization of electron density between bonding and non-bonding orbitals are causing the stabilization of donor-acceptor interactions [46]. The most important interactions in $\mathbf{S 1 1}$ resulting from $\sigma(C 3-C 4) \rightarrow \sigma^{*}(C 1-C 2), \quad \sigma(C 3-C 4) \rightarrow \sigma^{*}(C 5-C 6), \quad n(O 14) \rightarrow$ $R Y^{*}(C 13), n(017) \rightarrow \sigma^{*}(N 15-C 16)$ and $n(F 19) \rightarrow R Y^{*}(C 18)$ with the interaction energy $E^{(2)}$ of $20.25,21.84,16.71,21.93$ and $7.48 \mathrm{kcalmol}^{-1}$. 
Table 3. The type of orbital, its occupancy, the approximate composition of natural atomic hybrids of which NBO is composed along with the percentage composition of S and P orbitals in S11 obtained from the Natural Bond Orbitals (NBOs) analysis.

\begin{tabular}{|c|c|c|c|c|c|c|c|}
\hline Sr. No. & Bond A-B & Occupancy & $\mathbf{E D}_{\mathbf{A}}$ & $\mathbf{E D}_{\mathbf{B}}$ & NBO \% & $\mathrm{S} \%$ & $\mathbf{P} \%$ \\
\hline \multirow{2}{*}{1} & $\mathrm{BD}(\mathrm{C} 1 \mathrm{C} 2)$ & 197.535 & 48.96 & 51.04 & $0.6997 \mathrm{sp}^{1.92}+0.7144 \mathrm{sp}^{1.53}$ & $34.30,39.49$ & $65.70,60.51$ \\
\hline & $\mathrm{BD} *(\mathrm{C} 1 \mathrm{C} 2)$ & 0.2192 & 51.04 & 48.96 & $0.7144 \mathrm{sp}^{1.92}-0.6997 \mathrm{sp}^{1.53}$ & $34.30,39.49$ & $65.70,60.51$ \\
\hline \multirow{2}{*}{2} & $\mathrm{BD}(\mathrm{C} 1 \mathrm{H} 22)$ & 197.687 & 61.32 & 38.68 & $0.7831 \mathrm{sp}^{2.38}+0.6219 \mathrm{sp}$ & $29.57,100.00$ & 70.43 \\
\hline & $\mathrm{BD}^{*}(\mathrm{C} 1 \mathrm{H} 22)$ & 0.01281 & 38.68 & 61.32 & $0.6219 \mathrm{sp}^{2.38}-0.7831 \mathrm{sp}$ & $29.57,100.00$ & 70.43 \\
\hline \multirow{2}{*}{3} & $\mathrm{BD}(\mathrm{C} 2 \mathrm{O} 7)$ & 198.923 & 33.00 & 67.00 & $0.5745 \mathrm{sp}^{3.25}+0.8185 \mathrm{sp}^{2.37}$ & $23.52,29.69$ & $76.48,70.31$ \\
\hline & $\mathrm{BD}^{*}(\mathrm{C} 2 \mathrm{O} 7)$ & 0.03008 & 67.00 & 33.00 & $0.8185 \mathrm{sp}^{3.25}-0.5745 \mathrm{sp}^{2.37}$ & $23.52,29.69$ & $76.48,70.31$ \\
\hline \multirow{2}{*}{4} & BD (C6N8) & 198.291 & 37.25 & 62.75 & $0.6103 \mathrm{sp}^{2.81}+0.7922 \mathrm{sp}^{1.82}$ & $26.27,35.48$ & $73.73,64.52$ \\
\hline & BD* (C6N8) & 0.03814 & 62.75 & 37.25 & $0.7922 \mathrm{sp}^{2.81}-0.6103 \mathrm{sp}^{1.82}$ & $26.27,35.48$ & $73.73,64.52$ \\
\hline \multirow{2}{*}{5} & $\mathrm{BD}(\mathrm{C} 9 \mathrm{C} 10)$ & 198.549 & 48.20 & 51.80 & $0.6942 \mathrm{sp}^{2.32}+0.7197 \mathrm{sp}^{2.49}$ & $30.09,28.68$ & $69.91,71.32$ \\
\hline & BD* (C9C10) & 0.02805 & 51.80 & 48.20 & $0.7197 \mathrm{sp}^{2.32}-0.6942 \mathrm{sp}^{2.49}$ & $30.09,28.68$ & $69.91,71.32$ \\
\hline \multirow{2}{*}{6} & $\mathrm{BD}(\mathrm{C} 12 \mathrm{~N} 15)$ & 198.708 & 38.28 & 61.72 & $0.6187 \mathrm{sp}^{3.22}+0.7856 \mathrm{sp}^{1.68}$ & $23.72,37.72$ & $76.28,62.64$ \\
\hline & $\mathrm{BD} *(\mathrm{C} 12 \mathrm{~N} 15)$ & 0.02974 & 61.72 & 38.28 & $0.7856 \mathrm{sp}^{3.22}-0.6187 \mathrm{sp}^{1.68}$ & $23.72,37.72$ & $76.28,62.64$ \\
\hline \multirow{2}{*}{7} & BD (C13O14) & 198.973 & 36.25 & 63.75 & $0.6021 \mathrm{sp}^{1.95}+0.7984 \mathrm{sp}^{1.71}$ & $33.91,36.87$ & $66.09,63.13$ \\
\hline & $\mathrm{BD} *(\mathrm{C} 13 \mathrm{O} 14)$ & 0.01301 & 63.75 & 36.25 & $0.7984 \mathrm{sp}^{1.95}-0.6021 \mathrm{sp}^{1.71}$ & $33.91,36.87$ & $66.09,63.13$ \\
\hline \multirow{2}{*}{8} & BD (C16O17) & 199.160 & 36.90 & 63.10 & $0.6074 \mathrm{sp}^{1.98}+0.7944 \mathrm{sp}^{1.92}$ & $33.53,34.21$ & $66.47,65.79$ \\
\hline & $\mathrm{BD}^{*}(\mathrm{C} 16 \mathrm{O} 17)$ & 0.01604 & 63.10 & 36.90 & $0.7944 \mathrm{sp}^{1.98}-0.6074 \mathrm{sp}^{1.92}$ & $33.53,34.21$ & $66.47,65.79$ \\
\hline \multirow{2}{*}{9} & BD (C18F19) & 199.357 & 29.33 & 70.67 & $0.5415 \mathrm{sp}^{3.39}+0.8407 \mathrm{sp}^{3.61}$ & $22.78,21.78$ & $77.22,78.29$ \\
\hline & BD*( C18F19) & 0.10629 & 70.67 & 29.33 & $0.8407 \mathrm{sp}^{3.39}-0.5415 \mathrm{sp}^{3.61}$ & $22.78,21.78$ & $77.22,78.29$ \\
\hline 10 & LP O7 & 196.299 & & & $\mathrm{sp}^{1.43}$ & 41.11 & 58.89 \\
\hline 11 & LP N8 & 165.265 & & & $\mathrm{Sp}$ & 0.09 & 99.91 \\
\hline 12 & LP O14 & 197.756 & & & $\mathrm{Sp}^{0.58}$ & 63.12 & 36.88 \\
\hline 13 & LP N15 & 168.064 & & & $\mathrm{Sp}$ & 0.61 & 99.39 \\
\hline 14 & LP O17 & 198.144 & & & $\mathrm{sp}^{0.53}$ & 65.38 & 34.62 \\
\hline 15 & LP F19 & 199.112 & & & $\mathrm{sp}^{0.28}$ & 78.28 & 21.72 \\
\hline 16 & LP F20 & 199.125 & & & $\mathrm{sp}^{0.25}$ & 80.00 & 20.00 \\
\hline 17 & LP F21 & 199.020 & & & $\mathrm{sp}^{0.25}$ & 78.81 & 21.19 \\
\hline
\end{tabular}

Table 4. The charge transfer interaction of donor and acceptor orbitals is assessed by the $E^{2}$ energies which are given.

\begin{tabular}{|c|c|c|c|c|c|}
\hline \multirow{2}{*}{ Sr No. } & \multirow{2}{*}{ Donor NBO(i) } & \multirow{2}{*}{ Acceptor NBO(j) } & $E^{2}$ & $\boldsymbol{E}_{(j)}-\boldsymbol{E}_{(i)}$ & $\boldsymbol{F}_{(i j)}$ \\
\hline & & & (kcal/mol) & (a.u.) & (a.u.) \\
\hline 1 & \multirow{3}{*}{$\mathrm{BD}$ (1) $\mathrm{C} 1-\mathrm{C} 2$} & $\mathrm{BD}^{*}(1) \mathrm{C} 2-\mathrm{C} 6$ & 4.28 & 1.25 & 0.066 \\
\hline 2 & & $\mathrm{BD} *(1) \mathrm{C} 3-\mathrm{H} 23$ & 2.19 & 1.16 & 0.045 \\
\hline 3 & & $\mathrm{BD} *(1) \mathrm{C} 6-\mathrm{N} 8$ & 2.96 & 1.1 & 0.051 \\
\hline 4 & \multirow{2}{*}{$\mathrm{BD}(2) \mathrm{C} 3-\mathrm{C} 4$} & $\mathrm{BD}^{*}(2) \mathrm{C} 1-\mathrm{C} 2$ & 20.25 & 0.27 & 0.066 \\
\hline 5 & & BD*(2) C5 - C6 & 21.84 & 0.27 & 0.069 \\
\hline 6 & $\mathrm{BD}(1) \mathrm{C} 2$ - C6 & $\mathrm{BD} *(1) \mathrm{C} 5-\mathrm{C} 6$ & 4.11 & 1.27 & 0.065 \\
\hline 7 & $\mathrm{BD}(1) \mathrm{C} 3-\mathrm{H} 23$ & $\mathrm{BD} *(1) \mathrm{C} 1-\mathrm{C} 2$ & 3.44 & 1.07 & 0.054 \\
\hline 8 & \multirow{2}{*}{$\mathrm{BD}(1) \mathrm{C} 2$ - O7 } & $\mathrm{BD} *(1) \mathrm{C} 1-\mathrm{C} 3$ & 1.28 & 1.42 & 0.038 \\
\hline 9 & & BD*(1) C5 - C6 & 1.85 & 1.41 & 0.046 \\
\hline 10 & \multirow{2}{*}{ BD (1) C6 - N8 } & $\mathrm{BD} *(1) \mathrm{C} 1-\mathrm{C} 2$ & 1.86 & 1.36 & 0.045 \\
\hline 11 & & $\mathrm{BD} *(1) \mathrm{N} 8-\mathrm{C} 13$ & 1.79 & 1.21 & 0.042 \\
\hline 12 & $\mathrm{BD}(1) \mathrm{N} 8-\mathrm{C} 13$ & $\mathrm{BD}^{*}(1) \mathrm{C} 6-\mathrm{N} 8$ & 2.18 & 1.22 & 0.046 \\
\hline 13 & \multirow{2}{*}{$\mathrm{BD}$ (1) C13 - O14 } & BD*(1) N8 - C10 & 1.41 & 1.33 & 0.039 \\
\hline 14 & & $\mathrm{BD} *(1) \mathrm{C} 1-\mathrm{H} 31$ & 1.48 & 0.73 & 0.029 \\
\hline 15 & BD (1) N15 - C16 & $\mathrm{BD} *(1) \mathrm{C} 12-\mathrm{N} 15$ & 1.08 & 1.18 & 0.032 \\
\hline 16 & LP O7 & $\mathrm{RY}^{*} \mathrm{C} 2$ & 2.21 & 1.73 & 0.056 \\
\hline 17 & LP N8 & RY* C6 & 0.94 & 1.01 & 0.03 \\
\hline 18 & \multirow{2}{*}{ LP O14 } & $\mathrm{RY}^{*} \mathrm{C} 13$ & 16.71 & 1.65 & 0.148 \\
\hline 19 & & $\mathrm{BD}^{*}(1) \mathrm{C} 12-\mathrm{C} 13$ & 2.32 & 1.01 & 0.044 \\
\hline 20 & LP O17 & BD*(1) N15 - C16 & 21.93 & 0.68 & 0.111 \\
\hline 21 & LP F19 & $\mathrm{RY} * \mathrm{C} 18$ & 7.48 & 2.17 & 0.114 \\
\hline
\end{tabular}




\section{Electronic absorption spectra and HOMO-LUMO energy}

The energy gap of HOMO and LUMO determines the electrical properties of any molecule. HOMO-LUMO gap is also measure of electron conductivity [55]. Frontier molecular orbitals (FMO) along with other molecular orbitals are given in the Figure 6 calculated with TD-DFT. In the electronic transition, the electron from HOMO orbitals is excited to the LUMO orbitals [46]. From the Figure 6, it is clear that for the target molecule, the HOMO is mainly centered on the morpholine ring having oxygen and nitrogen (acting as donor moiety) and LUMO is centered on the benzene ring (acting as the acceptor moiety). The smaller HOMO-LUMO energy gap is reflecting the chemical stability of molecule. This stability is resulting from greater distribution of energy over the molecule due to greater pi electron distribution [56].

The electronic transitions, excitation energies and oscillation strength of S11 are computed with TD-DFT calculations. UV-Visible spectra were calculated by using different hybrid methods like B3LYP, P3PW91 and PBEPBE along with $6-311++G(d, p)$ are shown in the Figure 7. From Figure 7, is reflected that one distinct absorption band ranging from 220-320 nm with B3LYP/6-311++G(d,p), P3PW91/6-311++G(d,p) and around 260-420 nm with PBEPBE/6-311++G(d,p). The maximum absorption wavelength $\left(\lambda_{\max }\right)$, oscillation strength $(\mathrm{f})$ and excitation energies are given in the Table-5. For B3LYP, several possible electronic transitions are contribution to the absorption band but strong intensity transition has $\lambda_{\max }$ at $261.3 \mathrm{~nm}$ with $\mathrm{f}$ as 0.1441 and excitation energy is 4.746 $\mathrm{eV}$ corresponding to $\mathrm{H}$ to $\mathrm{L}+1$ transition. This transition can be assigned to intramolecular charge transfer from donating moiety to acceptor moiety via charge transfer axis. The major transition can be assign to $n \rightarrow \pi^{*}$ transition with considerable intramolecular charge transfer.
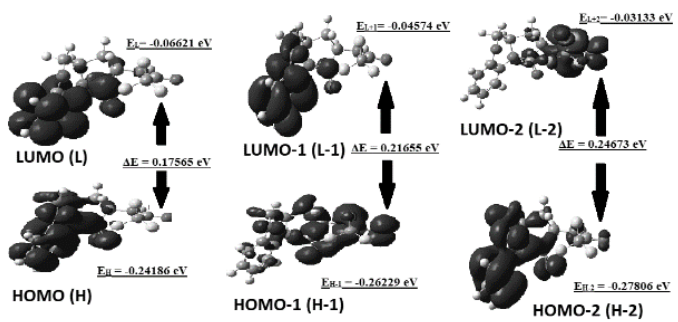

Figure 6. The frontier molecular orbitals of S11 in gas phase.

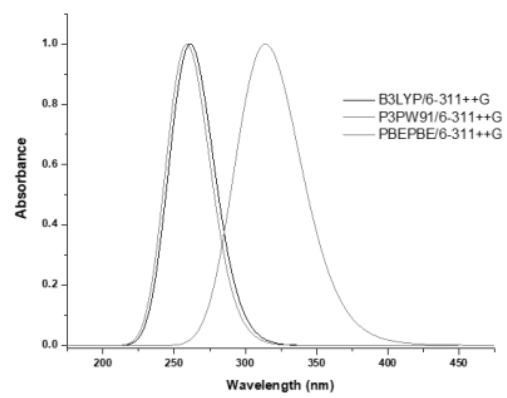

Figure 7. Computed UV-Visible absorption spectra of $S 11$ calculated in gas phase with DFT/B3LYP, DFT/P3PW91 and DFT/PBEPBE using 6-311++G (d,p).

Table 5. Electronic absorption spectra computed by TD-SCF at DFT level using different basis set for S-11 in gas phase

\begin{tabular}{|c|c|c|c|c|c|}
\hline \multirow{2}{*}{ Basis set } & \multicolumn{2}{|c|}{ Transition } & \multirow[t]{2}{*}{$\begin{array}{c}\text { Wavelength (nm) } \\
\text { Computed }\end{array}$} & \multirow{2}{*}{ Oscillator Strength (f) } & \multirow{2}{*}{ Energy $(e V)$} \\
\hline & Excited State & Contribution & & & \\
\hline \multirow{3}{*}{ DFT/B3LYP/6-311++G (d,p) } & Excited State-1 & $\mathrm{H} \rightarrow \mathrm{L}(70.4 \%)$ & 292.4 & 0.0005 & 4.214 \\
\hline & Excited State-2 & $\begin{array}{c}\mathrm{H}-1 \rightarrow \mathrm{L}+1(15.3 \%) \\
\mathrm{H}-1 \rightarrow \mathrm{L}+3(11.0 \%) \\
\mathrm{H} \rightarrow \mathrm{L}+1(63.5 \%)\end{array}$ & 261.3 & 0.1441 & 4.746 \\
\hline & Excited State-3 & $\begin{array}{l}\mathrm{H}-4 \rightarrow \mathrm{L}(49.2 \%) \\
\mathrm{H}-3 \rightarrow \mathrm{L}(36.3 \%) \\
\mathrm{H}-1 \rightarrow \mathrm{L}(33.7 \%)\end{array}$ & 256.6 & 0.0018 & 4.831 \\
\hline \multirow{3}{*}{ DFT/B3PW91/6-311++G (d,p) } & Excited State-1 & $\mathrm{H} \rightarrow \mathrm{L}(70.4 \%)$ & 288.7 & 0.0004 & 4.294 \\
\hline & Excited State-2 & $\begin{array}{c}\mathrm{H}-1 \rightarrow \mathrm{L}+1(17.8 \%) \\
\mathrm{H}-1 \rightarrow \mathrm{L}+3(13.1 \%) \\
\mathrm{H} \rightarrow \mathrm{L}+1(61.8 \%) \\
\mathrm{H} \rightarrow \mathrm{L}+2(15.0 \%)\end{array}$ & 258.8 & 0.1428 & 4.491 \\
\hline & Excited State-3 & $\begin{array}{l}\mathrm{H}-4 \rightarrow \mathrm{L}(43.1 \%) \\
\mathrm{H}-3 \rightarrow \mathrm{L}(52.1 \%) \\
\mathrm{H}-2 \rightarrow \mathrm{L}(10.8 \%) \\
\mathrm{H}-1 \rightarrow \mathrm{L}(15.5 \%)\end{array}$ & 255.2 & 0.0017 & 4.859 \\
\hline \multirow{3}{*}{ DFT/PBEPBE/6-311++G (d,p) } & Excited State-1 & $\mathrm{H} \rightarrow \mathrm{L}(70.7 \%)$ & 359.5 & 0.0003 & 3.267 \\
\hline & Excited State-2 & $\mathrm{H}-1 \rightarrow \mathrm{L}(62.6 \%)$ & 325.1 & 0.0052 & 3.814 \\
\hline & Excited State-3 & $\begin{array}{l}\mathrm{H}-4 \rightarrow \mathrm{L}(15.2 \%) \\
\mathrm{H}-2 \rightarrow \mathrm{L}(61.3 \%) \\
\mathrm{H}-1 \rightarrow \mathrm{L}(30.9 \%)\end{array}$ & 312.8 & 0.0384 & 3.964 \\
\hline
\end{tabular}

\section{Potential energy distribution}

The molecular electrostatic potential (MEP) surface is meaningful description of electron density of a molecule in space around a point. The charge density around a point is an indication of overall electrostatic effect resulting from electric and nuclear charge distributions and is correlated with the electronegativity, partial charges and dipole moment. MEP surface is also a powerful tool to give reactive polarity of the molecule [56,57]. It is an effective method to predict reactivity of electrophilic attack and potential of having hydrogen bonding interactions [58]. The red shade on MEP surface is site of electrophilic attack while, blue shade on MEP surface is site of nucleophilic attack, as it is the site with weaker shielding of nuclear charge. The green color share corresponds to zero electrostatic potential. Electrostatic potential is represented in MEP surface with the color gradient of red < orange < yellow $<$ green < blue. In the Figure 8, is given the mapped MEP surface of S11. The electrophilic reactivity is centered around oxygen atoms dominantly (red colored). The blue is the positive charge density region and is the region of nucleophilic reactivity with dominant centers around hydrogens. MEP surface of S11 specify the active sides for metallic bonding, probable hydrogen bonding and intermolecular interactions. 


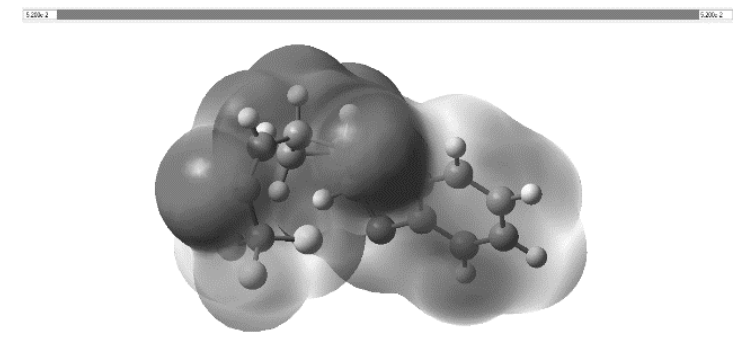

Figure 8. The molecular electrostatic potential surface mapping of S11.

\section{Thermodynamic Properties}

The dipole moment $(\mu)$ is providing the basis for probing the reactivity of a molecule [59]. DFT has been proven an effective tool to predict the dipole moment and thermodynamic parameters of organic compounds. The components of dipole moment $(\mathrm{x}, \mathrm{y}, \mathrm{z})$ are used to calculate the total dipole moment $\left(\mu=\left(\mu_{x}+\mu_{y}+\mu_{z}\right)^{1 / 2}\right)$ and hyper-polarizibilities [60]. In the Figure 9, the total dipole moment and its components are presented graphically calculated with the Moltran program. The dipole moment value is consistent with robust electronic transition behavior shown in absorption spectrum and MEP surface [61].

The change in the statistical thermodynamic functions (heat capacities $\left(\mathrm{C}_{\mathrm{v}}\right.$ and $\left.\mathrm{C}_{\mathrm{p}}\right)$, internal energy $(\Delta \mathrm{U})$, Gibb's free energy $(\Delta \mathrm{G})$, enthalpy $(\Delta \mathrm{H})$, entropy $(\Delta \mathrm{s})$ and contribution to partition function $(\mathrm{Q})$ ) were calculated at the temperature ranging from $10-500 \mathrm{~K}$ and are given in the Table 6 . The change in thermodynamic parameters $\left(\mathrm{C}_{\mathrm{p}}, \Delta \mathrm{H}, \Delta \mathrm{S}\right.$ and $\left.\Delta \mathrm{G}\right)$ are fitted with equation given below and correlation graph is shown in the Figure 9 .

$$
\begin{array}{ll}
\left(\mathrm{Cp}^{\mathrm{o}}\right)_{\text {total }}=32.73392+0.80902 \mathrm{~T}-0.000322 \mathrm{~T}^{2} & \left(\mathrm{R}^{2}=0.999\right) \\
\left(\Delta \mathrm{H}^{\mathrm{o}}\right)_{\text {total }}=615.25227+0.03024 \mathrm{~T}+0.000444 \mathrm{~T}^{2} & \left(\mathrm{R}^{2}=0.999\right) \\
\left(\Delta \mathrm{S}^{\circ}\right)_{\text {total }}=201.17892+1.83238 \mathrm{~T}-0.00286 \mathrm{~T}^{2} & \left(\mathrm{R}^{2}=0.999\right) \\
\left(\Delta \mathrm{G}^{\mathrm{o}}\right)_{\text {total }}=616.14459-0.23837 \mathrm{~T}-0.000626 \mathrm{~T}^{2} & \left(\mathrm{R}^{2}=0.999\right)
\end{array}
$$

The increase of temperature resulting in the increase of thermodynamic energies. This thermodynamic data is useful to predict direction of chemical reactivity in accordance with laws of thermodynamics [62]. Tricyclic compounds are known for their biological activities and this statistical thermodynamic data can be useful for further investigations of biological interactions as function of temperature.

(a)

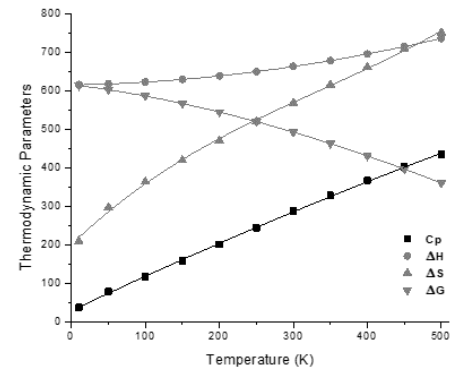

(b)

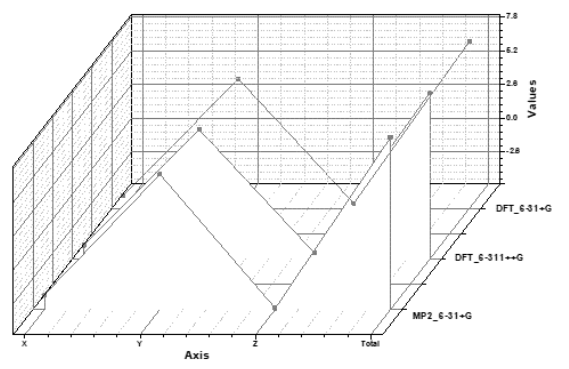

Figure 9. (a) Correlation graph of calculated thermodynamic parameters (heat capacity $[\mathrm{Cp}]$, enthalpy $[\Delta \mathrm{H}]$, entropy $[\Delta \mathrm{S}]$ and Gibbs free energy $[\Delta \mathrm{G}])$ at different temperatures; (b) Dipole moment calculated in three axis using MP2

\begin{tabular}{|c|c|c|c|c|c|c|c|}
\hline$\underset{(\mathbf{K})}{\text { Temperature }}$ & $\begin{array}{c}\mathbf{C}_{\mathbf{V}} \\
\left(\mathbf{J K}^{-1} \mathbf{m o l}^{-1}\right)\end{array}$ & $\begin{array}{c}\mathrm{C}_{\mathbf{P}} \\
\left(\mathrm{JK}^{-1} \mathbf{m o l}^{-1}\right)\end{array}$ & $\begin{array}{c}\Delta \mathbf{U} \\
\left(\mathbf{k J m o l} \mathbf{l}^{-1}\right)\end{array}$ & $\underset{\left(\mathbf{k J m o l ^ { - 1 }}\right)}{\Delta \mathbf{H}}$ & $\begin{array}{c}\Delta \mathbf{S} \\
\left(\mathbf{J K}^{-1} \mathbf{m o l} \mathbf{l}^{-1}\right)\end{array}$ & $\underset{\left(\mathbf{k J} \mathbf{J} \mathbf{l}^{-1}\right)}{\Delta \mathbf{G}}$ & Q \\
\hline 10 & 28.922 & 37.236 & 615.418 & 615.501 & 209.736 & 613.404 & $1.48 \mathrm{E}+09$ \\
\hline 50 & 70.723 & 79.037 & 617.493 & 617.909 & 297.63 & 603.027 & $4.72 \mathrm{E}+12$ \\
\hline 100 & 109.18 & 117.495 & 621.99 & 622.821 & 364.209 & 586.4 & $1.05 \mathrm{E}+15$ \\
\hline 150 & 149.732 & 158.046 & 628.452 & 629.699 & 419.432 & 566.784 & $7.00 \mathrm{E}+16$ \\
\hline 200 & 192.189 & 200.503 & 636.994 & 638.657 & 470.68 & 544.521 & $2.81 \mathrm{E}+18$ \\
\hline 250 & 235.541 & 243.856 & 647.686 & 649.765 & 520.071 & 519.747 & $8.61 \mathrm{E}+19$ \\
\hline 300 & 278.62 & 286.934 & 660.544 & 663.038 & 568.354 & 492.532 & $2.24 \mathrm{E}+21$ \\
\hline 350 & 320.058 & 328.372 & 675.521 & 678.431 & 615.726 & 462.926 & $5.24 \mathrm{E}+22$ \\
\hline 400 & 358.748 & 367.062 & 692.504 & 695.83 & 662.135 & 430.976 & $1.13 \mathrm{E}+24$ \\
\hline 450 & 394.078 & 402.393 & 711.339 & 715.081 & 707.443 & 396.731 & $2.26 \mathrm{E}+25$ \\
\hline 500 & 425.89 & 434.204 & 731.853 & 736.01 & 751.516 & 360.252 & $4.26 \mathrm{E}+26$ \\
\hline
\end{tabular}
and DFT.
Table 6. Thermodynamic functions calculations of S11 at DFT/B3LYP/6$311++\mathrm{G}$.

\section{CONCLUSION}

The current study involved the easy route of synthesis for S11 along with detailed computational study of structural, vibrational, charge distribution, HOMO-LUMO, UV-Visible, MEP surface, NBO and thermodynamic parameter analysis with B3LYP and MP2 level. All the assigned modes of vibration are in agreement with the expected range of vibration. The charge distribution calculated has good correspondence with electrostatic potential distribution found in the MEP surface. The UV-Visible absorption spectra showed shift with the basis due to definition of their polarization. The FMO analysis is reflecting the negative electrostatic potential is dominantly on oxygen and is possible fragment for the electrophilic attack. The statistical thermodynamic parameters computed on range of temperature and can be used for further investigations of biological activity of this molecule.

\section{ACKNOWLEDGEMENT}

Asim Mansha and Sadia Asim are grateful to Higher Education Commission (HEC) Islamabad, Pakistan for financial support (NRPU-2016-17/project number: 5613 and NRPU-2018-19/project number: 9922).

\section{REFERENCES}

1. A.F. Zahoor, M. Yousaf, R. Siddique, S. Ahmad, S.A.R. Naqvi, S.M.A. Rizvi, Synth. Commun. 47, 1021 (2017).

2. N. Giubellina, P. Stabile, G. Leval, A.D. Perboni, Z. Cimarosti, P. Westerduin, J.W.B. Cooke, Org. Process Res. Dev. 14, 859, (2010).

3. D. Zhou, B.L. Harrison, U. Shah, T.H. Andree, G.A. Hornby, R. Scerni, L.E. Schechter, D.L. Smith, K.M. Sullivan, R.E. Mewshaw, Bioorg. Med. Chem. Lett. 16, 1338, (2006).

4. T. Taverne, O. Diouf, P. Depreux, J.H. Poupaert, D. Lesieur, B. GuardiolaLemaître, P. Renard, M.-C. Rettori, D.-H. Caignard, B. Pfeiffer, J. Med. Chem. 41, 2010, (1998).

5. A.-S. Bourlot, I. Sánchez, G. Dureng, G. Guillaumet, R. Massingham, A. Monteil, E. Winslow, M.D. Pujol, J.-Y. Mérour, J. Med. Chem. 41, 3142, (1998).

6. S. Alper-Hayta, E. Akı-Sener, B. Tekiner-Gulbas, I. Yıldı, O. TemizArpac1, I. Yalcın, N. Altanlar, Eur. J. Med. Chem. 41, 1398, (2006).

7. A. Foroumadi, S. Emami, S. Mansouri, A. Javidnia, N. Saeid-Adeli, F.H. Shirazi, A. Shafiee, Eur. J. Med. Chem. 42, 985, (2007).

8. K.C. Majumdar, K. Ray, S. Ponra, Tetrahedron Lett. 51, 5437, (2010).

9. P.-F. Jiao, B.-X. Zhao, W.-W. Wang, Q.-X. He, M.-S. Wan, D.-S. Shin, J.Y. Miao, Bioorg. Med. Chem. Lett. 16, 2862, (2006).

10. M. Ghanbari, K. Jadidi, M. Mehrdad, N. Assempour, Tetrahedron 72, 4355, (2016).

11. B. Liu, M. Yin, H. Gao, W. Wu, H. Jiang, J. Org. Chem. 78, 3009, (2013).

12. A.T. Kurissery, G.A. Rajkumar, V.S. Arvapalli, V. Pitchumani, Tetrahedron Lett. 58, 3607, (2017).

13. U. Kazmaier, A.F. Zahoor, Arkivoc iv, 6, (2011).

14. A.F. Zahoor, S. Thies, U. Kazmaier, Beilstein J. Org. Chem. 7, 1299, (2011).

15. A.F. Zahoor, U. Kazmaier, Synthesis 7, 1059, (2011).

16. A.F. Zahoor, U. Kazmaier, Synthesis 18, 3020, (2011).

17. H. Varshney, A. Ahmad, A. Rauf, F.M. Husain, I. Ahmad, J. Saudi Chem. Soc. 21, S394, (2017). 
18. P. Zhang, E.A. Terefenko, A. Fensome, Z. Zhang, Y. Zhu, J. Cohen, R. Winneker, J. Wrobel, J. Yardley, Bioorg. Med. Chem. Lett. 12, 787, (2002).

19. M.J. Frisch, G.W. Trucks, H.B. Schlegel, G.E. Scuseria, M.A. Robb, J.R. Cheeseman, G. Scalmani, V. Barone, G.A. Petersson, H. Nakatsuji, X. Li, M. Caricato, A.V. Marenich, J. Bloino, B.G. Janesko, R. Gomperts, B. Mennucci, H.P. Hratchian, J.V. Ortiz, A.F. Izmaylov, J.L. Sonnenberg, F. Williams, Ding, F. Lipparini, F. Egidi, J. Goings, B. Peng, A. Petrone, T. Henderson, D. Ranasinghe, V.G. Zakrzewski, J. Gao, N. Rega, G. Zheng, W. Liang, M. Hada, M. Ehara, K. Toyota, R. Fukuda, J. Hasegawa, M. Ishida, T. Nakajima, Y. Honda, O. Kitao, H. Nakai, T. Vreven, K. Throssell, Jr. J.A. Montgomery, J.E. Peralta, F. Ogliaro, M.J. Bearpark, J.J. Heyd, E.N. Brothers, K.N. Kudin, V.N. Staroverov, T.A. Keith, R. Kobayashi, J. Normand, K. Raghavachari, A.P. Rendell, J.C. Burant, S.S. Iyengar, J. Tomasi, M. Cossi, J.M. Millam, M. Klene, C. Adamo, R. Cammi, J.W. Ochterski, R.L. Martin, K. Morokuma, O. Farkas, J.B. Foresman, D.J. Fox, Gaussian 16 Rev. B.01, Wallingford, CT, (2016).

20. A.D. Becke, J. Chem. Phys. 98, 5648, (1993).

21. C. Lee, W. Yang, R.G. Parr, Phys. Rev. B 37, 785, (1988).

22. M.P. Andersson, P. Uvdal, J. Phys. Chem. A 109, 2937, (2005).

23. J.P. Merrick, D. Moran, L. Radom, J. Phys. Chem. A 111, 11683, (2007).

24. M.H. Jamróz, Spectrochim. Acta A 114, 220, (2013).

25. M. Ali, A. Mansha, S. Asim, M. Zahid, M. Usman, N. Ali, J. Spectrosc. 2018, Article ID 9365153, (2018).

26. N. Ali, A. Mansha, S. Asim, A.F. Zahoor, S. Ghafoor, M.U. Akbar, J. Mol. Struct. 1156, 571, (2018).

27. A.E. Reed, F. Weinhold, J. Chem. Phys. 83, 1736, (1985).

28. J.P. Perdew, J.A. Chevary, S.H. Vosko, K.A. Jackson, M.R. Pederson, D.J. Singh, C. Fiolhais, Phys. Rev. B 46, 6671, (1992).

29. J.P. Perdew, K. Burke, M. Ernzerhof, Phys. Rev. Lett. 77, 3865, (1996).

30. N.X. Wang, A.K. Wilson, J. Phys. Chem. A 109, 7187, (2005).

31. P. Matczak, S. Wojtulewski, J. Mol. Model. 21, 41, (2015).

32. R.K. Singh, A.K. Singh, J. Mol. Struct. 1129, 128, (2017).

33. P. Rawat, R.N. Singh, J. Mol. Struct. 1097, 214, (2015).

34. M. Karabacak, M. Kurt, M. Cinar, S. Ayyappan, S. Sudha, N. Sundaraganesan, Spectrochim. Acta A 92, 365, (2012).

35. S. Gao, H.-T. Qu, F. Ye, Y. Fu, J. Chem. 2015, Article ID 268306, (2015).

36. V. Balachandran, V. Karpagam, B. Revathi, M. Kavimani, G. Ilango, Spectrochim. Acta A 150, 631, (2015).

37. J. Mohan, Organic spectroscopy: Principles \& applications, 2 nd ed., CRC Press, (2004).
38. B. Raja, V. Balachandran, B. Revathi, K. Anitha, Mater. Res. Innov. 23, 330, (2018).

39. S. Mühle, K.E. Süsse, D.G. Welsch, Phys. Lett. A 66, 25, (1978).

40. M.R. Anoop, P.S. Binil, S. Suma, M.R. Sudarsanakumar, Y.S. Mary, H.T. Varghese, C.Y. Panicker, J. Mol. Struct. 969, 48, (2010).

41. E. Kose, A. Atac, M. Karabacak, P.B. Nagabalasubramanian, A.M. Asiri, S. Periandy, Spectrochim. Acta A 116, 622, (2013).

42. R.M. Silverstein, F.X. Webster, D.J. Kiemle, D.L. Bryce, Spectrometric identification of organic compounds, 8th ed., Wiley, (2014).

43. G. Socrates, Infrared and Raman characteristic group frequencies: Tables and charts, 3rd ed., Wiley, 2004.

44. J. Tonannavar, J. Yenagi, V. Sortur, V.B. Jadhav, M.V. Kulkarni, Spectrochim. Acta A 77, 351, (2010).

45. A. Fu, D. Du, Z. Zhou, Spectrochim. Acta A 59, 245, (2003).

46. A.K. Singh, R.K. Singh, J. Mol. Struct. 1089, 191, (2015).

47. N.M. Kreienborg, C. Merten, Phys. Chem. Chem. Phys. 21, 3506, (2019).

48. X. Assfeld, J.-L. Rivail, Chem. Phys. Lett. 263, 100, (1996).

49. A.E. Reed, R.B. Weinstock, F. Weinhold, J. Chem. Phys. 83, 735, (1985).

50. D. Guo, L. Goodman, J. Phys. Chem. 100, 12540, (1996).

51. Q. Liu, L. Qiu, Y. Wang, G. Lv, G. Liu, S. Wang, J. Lin, J. Mol. Model. 22, 84, (2016).

52. V. Pophristic, L. Goodman, N. Guchhait, J. Phys. Chem. A 101, 4290, (1997).

53. F. Weinhold, Nature 411, 539, (2001).

54. C.-G. Liu, Z.-M. Su, X.-H. Guan, S. Muhammad, J. Phys. Chem. C 115, 23946, (2011).

55. I. Fleming, Molecular orbitals and organic chemical reactions, John Wiley \& Sons, (2011).

56. L. Padmaja, M. Amalanathan, C. Ravikumar, I. Hubert Joe, Spectrochim. Acta A 74, 349, (2009).

57. E. Scrocco, J. Tomasi, Adv. Quantum Chem. 11, 115, (1978).

58. P. Sjoberg, P. Politzer, J. Phys. Chem. 94, 3959, (1990).

59. A.A. Rashin, L. Young, I.A. Topol, S.K. Burt, Chem. Phys. Lett. 230, 182, (1994).

60. A.-M. Kelterer, A. Mansha, F.J. Iftikhar, Y. Zhang, W. Wang, J.-H. Xu, G. Grampp, J. Mol. Model. 20, 2344, (2014).

61. M. R. S. A. Janjua, Open Chem. 16, 978, (2018).

62. X.-W. Li, E. Shibata, T. Nakamura, Mater. Trans. 44, 1004, (2003). 